\section{Calcificación vascular arterial detectada en radiografía panorámica digital}

\section{Vascular arterial calcification detected in digital panoramic radiography}

\section{Carta al Editor}

Fernando Russbelts Sthorayca Retamozo ${ }^{1, a}$, Vilma Elizabeth Ruiz García de Chacón 1,a,b

${ }^{1}$ Universidad Peruana Cayetano Heredia, Facultad de Estomatología, Lima, Perú.

a Cirujano Dentista.

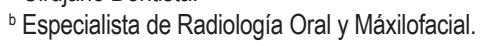

\title{
Correspondencia:
}

Fernando Russbelts Sthorayca Retamozo: fernando.

sthorayca@upch.pe

Calle Bolívar 434. Tacna-Perú.

ORCID: 0000-0001-8257-7265

\section{Coautora:}

Vilma Elizabeth Ruiz García de Chacón

vilma.ruiz.g@upch.pe

\section{Conflicto de intereses: ninguno}

Recibido: 24/11/19

Aprobado: 03/12/19

Publicado: 24/02/20

\section{Sr. Editor.}

La calcificación arterial puede ocurrir en la túnica íntima como en la túnica media de los vasos sanguíneos. La primera es parte de la aterosclerosis, que está determinada por la acumulación de placas calcificadas dentro de la luz del vaso sanguíneo. En cuanto a la calcificación de la túnica media o también conocida como arteriosclerosis de Monckeberg, es una enfermedad degenerativa y no inflamatoria que está caracterizada por la calcificación distrófica y el endurecimiento progresivo de las fibras musculares, por lo que el vaso pierde su elasticidad sin obstruir o estrechar su luz ${ }^{1-3}$.

La evidencia científica reporta que la arteriosclerosis de Monckeberg se presenta con mayor frecuencia en pacientes adultos mayores y es más prevalente en casos de diabetes mellitus y/o enfermedad renal crónica concomitante. La etiología de esta entidad sigue sin estar clara, sin embargo, se puede identificar como hallazgo radiográfico mediante exámenes odontológicos rutinarios como son la radiografía panorámica, bite wing o periapicales ${ }^{4,5}$.

Al examen clínico generalmente se presenta de manera asintomática, pero en cuanto al examen radiográfico se observa como una imagen radiopaca proyectada en tejidos blandos que puede tener un curso recto o un camino tortuoso dando un patrón muy parecido a las vías del ferrocarril 1,6 (Figura).

Es fundamental que el odontólogo tenga conocimiento de esta condición vascular de importancia sistémica y su hallazgo incidental en exámenes radiográficos, ya que por sutil que sean los signos, debe poder reconocerlos 


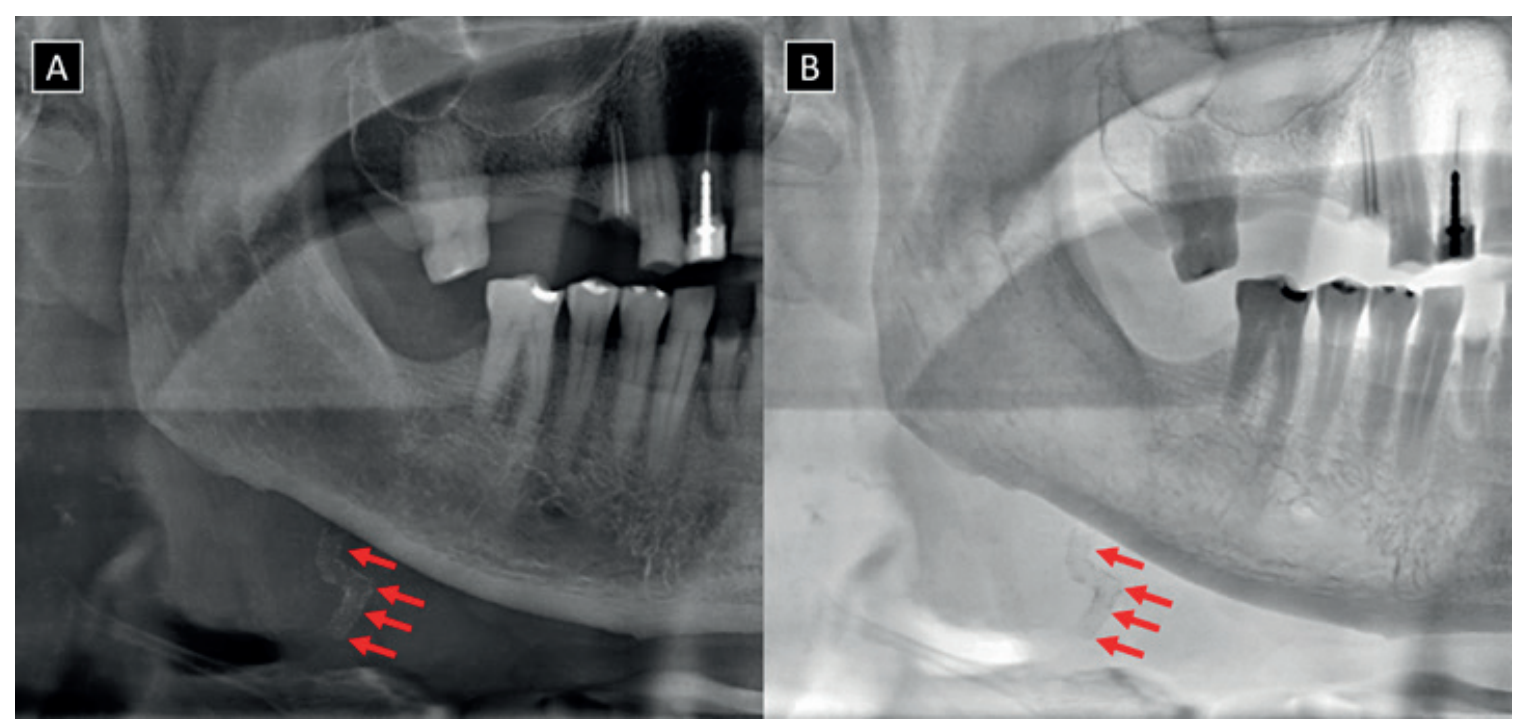

Figura. A y B. Radiografía panorámica recortada donde se evidencia una imagen radiopaca de camino tortuoso proyectada en tejidos blandos a nivel caudal del cuerpo mandibular derecho, signos radiográficos característicos de calcificación de la arteria facial. Imagen tomada del archivo del Servicio de Radiología Oral y Maxilofacial de la FE- UPCH

y asociarlos con ciertas enfermedades de fondo para que el paciente pueda ser derivado y ser tratado por el médico especialista, ya que muchas veces este es un signo inicial de una enfermedad de fondo desconocida por el mismo paciente y por lo tanto no reportada en los antecedentes de la historia clínica.

\section{Referencias bibliográficas}

1. Tahmasbi-Arashlow M, Barghan S, Kashtwari D, Nair MK. Radiographic manifestations of Mönckeberg arteriosclerosis in the head and neck region. Imaging Sci Dent. 2016;46(1):53-6.

2. Omami G. Monckeberg Arteriosclerosis: A Telltale Sign. J Oral Maxillofac Surg. 2017;75(11):2383-4.
3. Frazier JJ, Casian R, Benson BW. Mönckeberg medial calcinosis of the infraorbital arteries: a first case report. Oral Surg Oral Med Oral Pathol Oral Radiol. 2018;125(2):e31-e35.

4. Couri CE, da Silva GA, Martinez JA, Pereira Fde A, de Paula FJ. Mönckeberg's sclerosis - is the artery the only target of calcification? BMC Cardiovasc Disord. 2005;12(5):3-4.

5. Amann K. Media calcification and intima calcification are distinct entities in chronic kidney disease. Clin J Am Soc Nephrol. 2008;3(6):1599-605.

6. Castling B, Bhatia S, Ahsan F. Mönckeberg's arteriosclerosis: vascular calcification complicating microvascular surgery. Int J Oral Maxillofac Surg. 2015;44(1):34-6. 